\title{
New sex-determination system in the genus Panstrongylus (Hemiptera: Reduviidae) revealed by chromosomal analysis of Panstrongylus lutzi
}

Silvia Menezes dos Santos', Silvia das Graças Pompolo², Teresa Cristina Monte Gonçalves', Simone Patricia Carneiro de Freitas ${ }^{1}$, Elizabeth Ferreira Rangel ${ }^{1}$ and Jacenir Reis dos Santos-Mallet ${ }^{1 *}$

\begin{abstract}
Background: Panstrongylus lutzi (Neiva \& Pinto, 1923) is a triatomine species native to Caatinga habitats in northeastern Brazil. It is considered an important vector of Chagas disease in this region, presenting high rates of natural infection with Trypanosoma cruzi Chagas, 1909, and readily invading houses by flight. This study describes a previously unknown chromosomal sex system in the genus Panstrongylus based on P. lutzi.

Methods: Fifth-instar and male adults of $P$. lutzi originating from municipality of Várzea Alegre, Ceará (Brazil) were analysed. Chromosomal analyses of male meiotic process were done by Giemsa staining.

Results: Chromosomal analyses of male meiosis reveal a diploid chromosome number of 24 chromosomes (20 autosomes plus X1X2X3Y). During meiotic prophase I, the sex chromosomes remained close together, forming four heteropycnotic chromocenters in zygotene, and a single chromocenter in pachytene and diplotene. Still at the diplotene stage, each one of the ten autosomal bivalents showed an evident chiasma. In metaphase I, the four sex chromosomes appeared clearly separated. The three $X$ chromosomes were the smallest of the complement and isopycnotic with respect to the Y chromosome. Two bivalents appear larger, whereas the other eight showed no significant difference in size.
\end{abstract}

Conclusion: Karyotype analysis of $P$. lutzi revealed a new sex system in the genus Panstrongylus. This result is of utmost importance to karyosystematics of $P$. lutzi, and demonstrates the need for further studies of this type in the subfamily Triatominae.

Keywords: Cytogenetics, Karyosystematics, Triatominae

\section{Background}

Subfamily Triatominae includes more than 150 living species and two fossils [1]. All are capable of transmitting the parasite Trypanosoma cruzi Chagas, 1909, the etiological agent of Chagas disease. Most species are considered of little to no epidemiological importance, described as either secondary or occasional vectors [2]. Panstrongylus lutzi is a species restricted to the Caatinga

\footnotetext{
* Correspondence: jacenir@ioc.fiocruz.br

${ }^{1}$ Laboratório Interdiciplinar de Vigilância Entomológica em Diptera e Hemiptera, Instituto Oswaldo Cruz - Fiocruz, Av. Brasil 4365, 21045-900 Rio de Janeiro, RJ, Brazil

Full list of author information is available at the end of the article
}

biome in north-eastern Brazil, and participates in the enzootic cycle of this disease. It has high rates of natural infection with $T$. cruzi, and readily invades houses by flight $[3,4]$.

The Hemiptera are cytogenetically characterized by presenting holocentric chromosomes, where the centromere is diffusely distributed $[5,6]$. Cytogenetic techniques and analysis of chromosome behaviour during meiosis have provided characters for species differentiation [7-12] and determination of interspecific variation $[8,13-16]$, and have contributed to studies of evolutionary relationships $[9,17,18]$. Several characters such as chromosome number, system 
of sex determination, and the comparative size of autosomes have been proven useful for differentiating triatomine species.

Karyotypic studies of the Triatominae were initiated using the karyotype description of Triatoma sanguisuga [19]. In 1950, cytogenetic studies were resumed and new karyotypes were described in the literature [20]. Ueshima (1966) [6] initiated cytotaxonomy in triatomines by describing the diploid chromosome set of twenty new species, proposing that 22 chromosomes $(20 \mathrm{~A}+\mathrm{XY})$ is the type number for the Triatominae and emphasizing the importance of cytogenetic studies for the taxonomy of these vectors. Currently, 88 species (ranging from 21 to 25 chromosomes) have described karyotypes [21].

Cytogenetic analysis of the genus Panstrongylus was initiated in 1950 with the karyotype description of Panstrongylus megistus [20]. Crossa et al. [14] conducted an important cytotaxonomic study of genus Panstrongylus, characterizing six species: Panstrogylus chinai, Panstrongylus rufotuberculatus, Panstrongylus lignarius, Panstrongylus geniculatus, Panstrongylus tupynambai and P. megistus. However, there are 14 living Panstrongylus species [1] and an understanding of the cytogenetic characteristics of the other eight species is of extreme importance for describing taxonomy and evolutionary relationships in this group of vectors.

To increase knowledge of chromosomal behaviour in the genus Panstrongylus, we characterized for the first time the meiotic cycle of $P$. lutzi using a conventional staining technique.

\section{Methods}

Twenty male adults and 20 fifth-instar P. lutzi nymphs were analyzed. Sex was determined by genital plate morphology. The insects originated in the municipality of Várzea Alegre, Ceará, and were kept in colonies in the Interdisciplinary Laboratory for Entomological Vigilance of Diptera and Hemiptera, Department of Medical and Forensic Entomology, Oswaldo Cruz Institute, Rio de Janeiro, Brazil.

Insects were dissected and testes removed using Ringer's solution. Testes were then mounted on slides using methodology adapted from Imai et al. [22]; this is to our knowledge the first use of these methods in a non-hymenopteran insect. Briefly, the material is transferred to a histological slide which is flooded with fixative I (4:3:3 water:ethanol:acetic acid). The slides are then transferred to a stereomicroscope and two drops of fixative I are added, initiating separation. Before the material is completely dry, two drops of fixative II (1:1 ethanol:acetic acid) are added, followed by two drops of fixative III (100\% acetic acid). Pieces of filter paper were placed on the edges of the slides to remove excess fixative solution. Slides were then dried at room temperature for $24 \mathrm{~h}$ and stained with Giemsa diluted in Soerensen buffer ( $\mathrm{pH}$ 6.8, 1:30 dilution) for five minutes at room temperature.

Meiotic cells were observed and images captured using an Olympus BX 60 microscope with a 100× objective, equipped with a $\mathrm{Q}$ Color 3 Olympus $^{\oplus}$ image capture system.

\section{Results}

Analysis of male meiotic metaphases revealed a diploid chromosome number of 24 chromosomes, including 20 autosomes and four sex chromosomes (X1X2X3Y). During the first meiotic prophase, the sex chromosomes were kept close together forming four heteropycnotic chromocenters in zygotene (Fig. 1a) or as a single chromocenter in pachytene and diplotene (Fig. 1b, c). Still at the diplotene stage, each one of the ten bivalents showed an evident chiasma (Fig. 1c). In metaphase I, four sex chromosomes showed to be separated: three $\mathrm{X}$ chromosomes of similar size were the smallest of chromosome complement and appeared to be isopycnotic regarding $\mathrm{Y}$ chromosome (Fig. 1d). The autosomes showed two largest bivalents, whereas the others had no significant differences in size. In anaphase I, the sex chromosomes exhibited equational segregation while the autosomes showed reductional segregation (Fig. 1e). In metaphase II (Fig. 1f), the four sex chromosomes were located in the centre of the metaphase plate.

\section{Discussion}

The analysis of cytogenetic characteristics supports the hypothesis that there are distinct chromosomal lines within the Triatominae.

However, many monophyletic groups present the same cytogenetic characteristics, as in the phyllosoma complex [9] and in brasiliensis, rubrovaria and matogrossensis subcomplexes [18]. Furthermore, similarity of chromosomal characteristics among species in the tribe Rhodniini suggests a monophyletic origin [16], as well as the fact that all species have the same number of chromosomes (22) and the same system of sex determination (XY) [17].

The Triatomini tribe presents an extensive variation in several chromosomal characters supporting the existence of different evolutionary lines, with widely varying degrees of chromosomal differentiation depending on the species group considered. This group presents three different sex systems in males: $\mathrm{XY}$, $\mathrm{X} 1 \mathrm{X} 2 \mathrm{Y}$ and $\mathrm{X} 1 \mathrm{X} 2 \mathrm{X} 3 \mathrm{Y}$. In the genus Panstrongylus, all species studied to date showed only X1X2Y sex system [14]. In this paper we included a new sex 

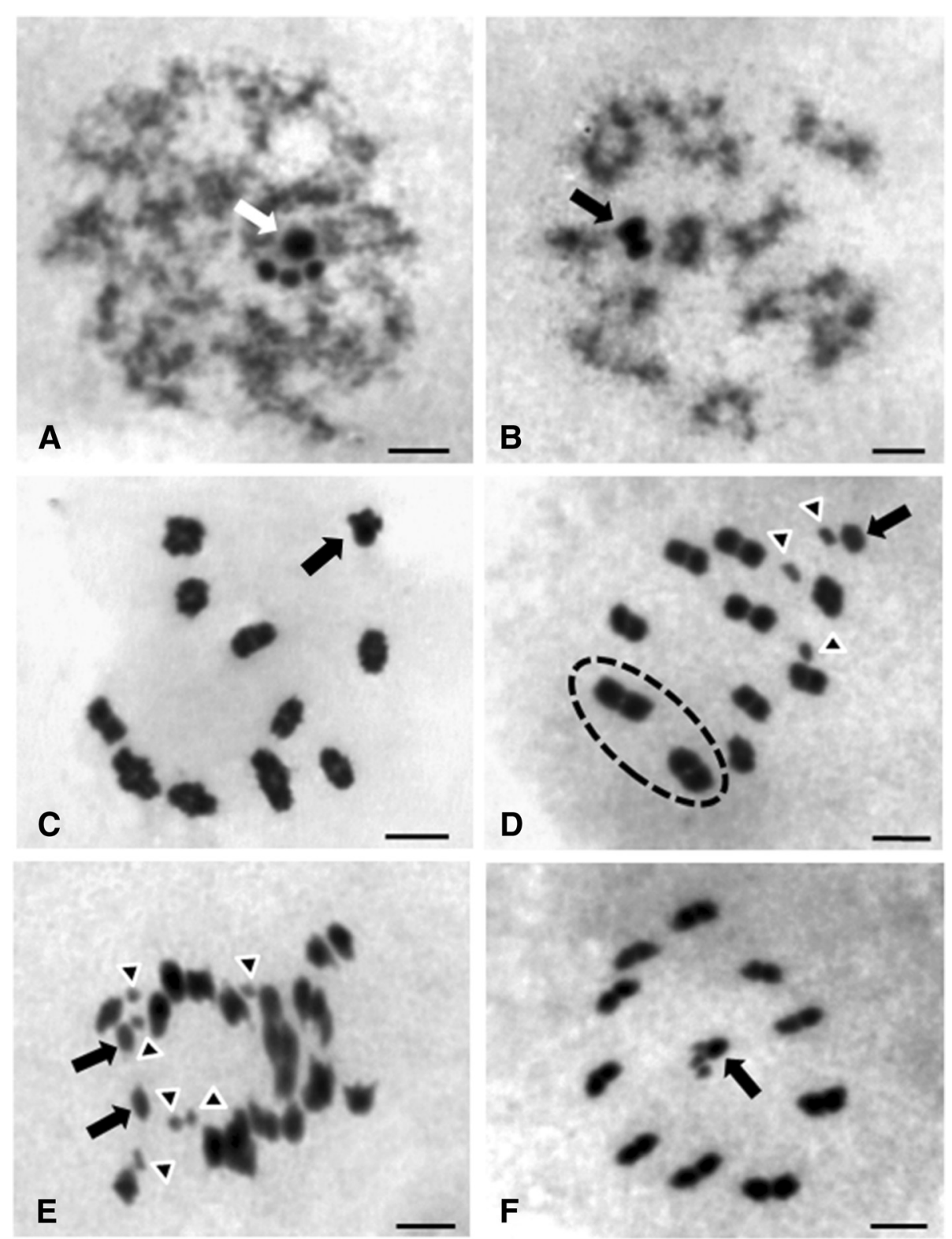

Fig. 1 Meiosis in Panstrongylus lutzi males (Giemsa staining). $2 n=20 A+X_{1} X_{2} X_{3} Y$ a Zygotene with four heteropycnotic chromocenters (arrow). b Pachytene with a single chromocenter formed by sex chromosomes (arrow). c Late Diplotene. Each one of the ten bivalents showed one chiasma while the sex chromosomes appeared close associated (arrow) $\mathbf{d}$ Metaphase I showing ten bivalents, three $X$ chromosomes $\left(X_{1} X_{2} X_{3}\right)$ (arrowheads) and $Y$ chromosome (arrow). The dashed circle indicates two major bivalents. e Anaphase I. Equational division of sex chromosomes indicating $X_{1} X_{2} X_{3}$ chromosomes (arrowheads) and $Y$ chromosome (arrow). $\mathbf{f}$ Metaphase II with ten half-bivalents and the four sex chromosomes forming a pseudotetravalent (arrow). Scale-bars: $5 \mu \mathrm{m}$

system of $P$. lutzi (X1X2X3Y) differing from those previously described within this genus. The variation in the number of sex chromosomes in P. lutzi can be explained by fragmentation of the original $\mathrm{X}$ chromosome [6], or as resulting from other chromosomal rearrangements [23]. Cytogenetic analyses with other banding techniques could provide valuable information about the origin of the additional $\mathrm{X}$ chromosome in P. lutzi.
Molecular analyses and experimental hybridization among P. lutzi and other Panstrongylus spp. are needed to assess the evolutionary relationships of this genus.

\section{Conclusion}

Karyotypic analysis of $P$. lutzi revealed a new sex system in the genus Panstrongylus. This result is of utmost importance for karyosystematics in triatomines in order to 
clarify the taxonomic identification and chromosome evolution within this insect group.

\section{Acknowledgement}

Financial support was provided by the Conselho Nacional de Desenvolvimento Científico e Tecnológico (CNPq), and the Coordenação de Aperfeiçoamento de Pessoal de Nível Superior (CAPES).

\section{Authors' contributions}

JRSM coordinated the study. SMS and SGP are responsible for experimental design and data analysis. TCMG, SPCF and EFR collected data. All authors collaborated to interpret data and participated in writing, revision, and all approved the final draft of the manuscript.

\section{Competing interests}

The authors declare that they have no competing interests.

\section{Author details}

${ }^{1}$ Laboratório Interdiciplinar de Vigilância Entomológica em Diptera e Hemiptera, Instituto Oswaldo Cruz - Fiocruz, Av. Brasil 4365, 21045-900 Rio de Janeiro, RJ, Brazil. ²Departamento de Biologia Animal, Laboratório de Citogenética de Insetos, Universidade Federal de Viçosa, Avenida PH Rolfs, s/n Campus Universitário, 36570-000 Viçosa, MG, Brazil.

Received: 28 July 2015 Accepted: 5 May 2016

Published online: 21 May 2016

\section{References}

1. Galvão C, Paula AS. Sistemática e evolução dos vetores. In: Galvão C, editor. Vetores da doença de Chagas no Brasil [on line]. Curitiba: Sociedade Brasileira de Zoologia; 2014. p. 26-32.

2. Schofield CJ, Jannin J, Salvatella R. The future of Chagas disease control. Trends Parasitol. 2006;21:583-88.

3. Freitas SPC, Freitas ALC, Gonçalves TCM. Occurrence of Panstrongylus lutzi, in peridomiciliary areas, State of Ceará, Brazil. Rev Saude Publica. 2004;38(4): 579-80.

4. Caranha L, Lorosa ES, Rocha DS, Jurberg J, Galvão C. Feeding sources evaluation of Panstrongylus lutzi (Neiva \& Pinto, 1923) (Hemiptera: Reduvidae: Triatominae) in the state of Ceará. Rev Soc Brasil Med Trop. 2006:39(4):347-51.

5. Hughes-Schrader S, Schrader F. The kinetochore of the Hemiptera. Chromosoma. 1961;12:327-50.

6. Ueshima NK. Cytotaxonomy of the Triatominae (Reduviidae, Hemiptera). Chromosoma. 1966;18:97-122.

7. Panzera F, Pérez R, Panzera Y, Alvarez F, Scvortzoff E, Salvatella R. Karyotype evolution in holocentric chromosomes of three related species of triatomines (Hemiptera-Reduviidae). Chromosome Res. 1995:3:143-50.

8. Panzera F, Hornos S, Pereira J, Cestau R, Canale D, Diotaiuti L, Dujardin JP, Pérez R. Genetic variability and geographic differentiation among three species of triatomine bugs (Hemiptera-Reduviidae). Am J Trop Med Hyg 1997:57:732-39.

9. Panzera F, Pérez R, Panzera Y, Ferrandis I, Ferreiro MJ, Calleros L. Cytogenetics and genome evolution in the subfamily Triatominae (Hemiptera, Reduviidae). Cytogenet Genome Res. 2010;128:77-87.

10. Santos SM, Lopes CM, Dujardin JP, Panzera F, Pérez R, Carbajal de la Fuente AL, Pacheco RS, Noireau F. Evolutionary relationships based on genetic and phenetic characters between Triatoma maculata, Triatoma pseudomaculata and morphologically related species (Reduviidae: Triatominae. Infect Genet Evol. 2007;7:469-75.

11. Alevi KCC, Mendonça PP, Pereira NP, Fernandes ALVZ, Rosa JA, AzeredoOliveira MTV. Analysis of spermiogenesis like a tool in the study of the triatomines of the Brasiliensis subcomplex. C R Biol. 2013:336:46-50.

12. Alevi KCC, Mendonça PP, Pereira NP, Guerra AL, Facina CH, Rosa JA Azeredo-Oliveira MTV. Distribution of constitutive heterochromatin in two species of triatomines: Triatoma lenti Sherlock and Serafim (1967) and Triatoma sherlocki Papa, Jurberg, Carcavallo, Cerqueira \& Barata (2002). Infect Genet Evol. 2013;13:301-03.

13. Panzera F, Dujardin JP, Nicolini P, Caraccio MN, Rose V, Tellez T, Bermúdez H, Bargues MD, Mas-Coma S, O'Connor JE, Pérez R. Genomic changes of Chagas disease vector, South America. Emerg Infect Dis. 2004;10:438-46.
14. Crossa RP, Hernández M, Caraccio MN, Rose V, Valente SAS, Valente VC, Mejía JM, Ângulo VM, Ramírez CMS, Roldán J, Vargas F, Wolff M, Panzera F. Chromosomal evolution trends of the genus Panstrongylus (Hemiptera, Reduviidae), vectors of Chagas disease. Infect Genet Evol. 2002:2:47-56.

15. Gomez-Palacio A, Jaramillo-Ocampo N, Triana-Chavez O, Saldanã AA, Calzada J, Pérez R, Panzera F. Chromosome variability in the Chagas disease vector Rhodnius pallescens (Hemiptera, Reduviidae, Rhodniini). Mem Inst Oswaldo Cruz. 2008;103:160-64.

16. Pita S, Panzera F, Ferrandis I, Galvão C, Gómez-Palacio A, Panzera Y. Chromosomal divergence and evolutionary inferences in Rhodniini based on the chromosomal location of ribosomal genes. Mem Inst Oswaldo Cruz 2013;108:376-82.

17. Panzera Y, Pita S, Ferreiro MJ, Ferrandis I, Lages C, Pérez R, Silva AE, Guerra M, Panzera F. High dynamics of rDNA cluster location in kissing bug holocentric chromosomes (Triatominae, Heteroptera). Cytogenet Genome Res. 2012;138:56-67.

18. Alevi KCC, Rosa JA, Azeredo-Oliveira MTV. Cytotaxonomy of the Brasiliensis subcomplex and the Triatoma brasiliensis complex (Hemiptera: Reduviidae: Triatominae). Zootaxa. 2014;3838:583-89.

19. Payne F. Some new types of chromosome distribution and their relation to sex. Biol Bull. 1909;16:119-66.

20. Schreiber G, Pellegrino J. Eteropicnosi di autosomi come possibile meccanismo di speciazione. Sci Genetic. 1950;3:215-26.

21. Alevi KCC, Borsatto KC, Moreira FFF, Jurberg J, Azeredo-Oliveira MTV. Karyosystematics of Triatoma rubrofasciata (De Geer, 1773) (Hemiptera, Reduviidae, Triatominae). Zootaxa. 2015:3994:433-38.

22. Imai HT, Taylor RW, Crosland MWJ, Crozier RH. Modes of spontaneous evolution in ants with reference to minimum interaction hypothesis. Jpn J Genet. 1988;63:159-85.

23. Pérez R, Calleros L, Rose V, Lorca M, Panzera F. Cytogenetic studies in Mepraia gajardoi (Hemiptera, Reduviidae). Chromosome behavior in a spontaneous translocation mutant. Europ J Entomol. 2004;101:211-18.

\section{Submit your next manuscript to BioMed Central and we will help you at every step:}

- We accept pre-submission inquiries

- Our selector tool helps you to find the most relevant journal

- We provide round the clock customer support

- Convenient online submission

- Thorough peer review

- Inclusion in PubMed and all major indexing services

- Maximum visibility for your research

Submit your manuscript at www.biomedcentral.com/submit 